\title{
INCLUSÃO E EDUCAÇÃO INFANTIL
}

\author{
INCLUSIÓN Y EDUCACIÓN INFANTIL
}

\section{INCLUSION AND EARLY CHILDHOOD EDUCATION}

\author{
Claudia Regina Mosca GIROTO ${ }^{1}$ \\ Fabiana Cristina Frigieri de VITTA ${ }^{2}$ \\ Luciana Aparecida de ARAUJO ${ }^{3}$
}

O direito de todos à educação de qualidade tem se constituído em meta nas políticas públicas sociais, frente às desigualdades engendradas pelas/nas condições de existência humana, o que, sem dúvida, configurou avanços direcionados a minimizar essas desigualdades. Entretanto, equívocos e contradições persistem, no que diz respeito à esfera educacional, tensionando o debate acerca das possibilidades de superação dessas desigualdades e de garantia desse direito, determinando, também, retrocessos que, indubitavelmente, afetam a inclusão de crianças da Educação Infantil nos processos educativos, a depender da maneira como tais processos são compreendidos e de como isso se refrata no trabalho educativo.

Mais recentemente, a reorganização de sistemas educacionais, na perspectiva inclusiva, que contempla a diversidade constituída nas/pelas relações sociais e as diferenças como constitutivas do sujeito, prevê que o trabalho educativo na Educação Infantil leve em conta a heterogeneidade do público escolar que a frequenta.

Dessa perspectiva, o trabalho educativo na Educação Infantil, num contexto inclusivo, sob os princípios da universalização do acesso à educação, da igualdade de direitos no acesso às oportunidades e da equidade, pressupõe que sejam consideradas as especificidades das crianças, seus distintos modos de apropriação do conhecimento e os diferentes contextos

${ }^{1}$ Universidade Estadual Paulista (UNESP), Marília - SP - Brasil. Docente do Programa de Pós-Graduação em Educação (PPGE) e do Departamento de Educação Especial, Faculdade de Filosofia e Ciências (FFC). Docente do Programa de Pós-Graduação em Educação Escolar (PPGEE), Faculdade de Ciências e Letras (FCLAr). Doutora em Educação. ORCID: <https://orcid.org/0000-0001-6267-8085>. E-mail: claudia.mosca@unesp.br

${ }^{2}$ Universidade Estadual Paulista (UNESP), Marília - SP - Brasil. Docente do Departamento de Educação Especial, Faculdade de Filosofia e Ciências (FFC), e do Programa de Pós-Graduação em Educação Escolar (PPGEE), Faculdade de Ciências e Letras (FCLAr). Doutora em Educação Especial. ORCID: <https://orcid.org/0000-0001-9545-7588>.E-mail: fabiana.vitta@unesp.br

${ }^{3}$ Universidade Estadual Paulista (UNESP), Marília - SP - Brasil. Docente do Programa de Pós-Graduação em Educação (PPGE) e do Departamento de Didática, Faculdade de Filosofia e Ciências (FFC). Doutora em Educação. ORCID: <https://orcid.org/0000-0003-1147-5039>. E-mail: luciana.penitente @ unesp.br 
escolares, de modo que as diferenças sejam valorizadas. Pressupõe, ainda, conferir visibilidade à criança como sujeito de direitos e produtora de cultura.

No entanto, a compreensão sobre a Educação Infantil numa perspectiva inclusiva ainda está longe de ser sistematizada no contexto educacional brasileiro. São muitos os limites e desafios que se colocam à garantia de educação de qualidade a todas as crianças, bem como é grande o abismo entre as políticas públicas e sua operacionalização na realidade escolar para que esse direito seja assegurado.

O dossiê "Inclusão e Educação Infantil", frente aos avanços, limites e desafios engendrados na constituição de uma Educação Infantil inclusiva, objetiva promover reflexões acerca dessa temática, a partir de referenciais políticos, do mapeamento das formas de organização de sistemas educacionais inclusivos com enfoque em aspectos que perpassam a Educação Infantil, da formação de professores e das práticas pedagógicas inclusivas constituídas nessa modalidade educacional.

Apresentado pela Revista Ibero-Americana de Estudos em Educação (RIAEE), este dossiê contempla 17 artigos, no formato de ensaio teórico, revisão bibliográfica, análise documental e relatos de pesquisas, de autoria de pesquisadores vinculados a instituições de ensino superior internacional (Universidad del Salvador (USAL)/Buenos Aires/Argentina) e nacionais, das diferentes regiões do Brasil: Universidade Federal do Amazonas (UFAM/AM); Universidade Federal de Alagoas (UFAL/AL); Universidade do Estado do Pará (UEPA/PA); Universidade Federal de Catalão/GO; Universidade Federal da Grande Dourados (UFGD/MS); Universidade Federal de Uberlândia (UFU/MG); Universidade Estadual Paulista (UNESP/SP); Universidade de São Paulo (USP/SP); Universidade Federal de São Paulo (UNIFESP/Santos/SP); Universidade Federal de São Carlos (UFSCar/SP); e Universidade Federal do Rio Grande do Sul (UFRGS/RS).

"Políticas, formação docente e práticas pedagógicas: reflexões acerca de uma Educação Infantil inclusiva", de autoria de Cleriston Izidro dos Anjos, Shirley Silva e Cleber Nelson de Oliveira Silva, contempla uma análise da tríade política educacional, formação docente e práticas pedagógicas compreendida a partir dos contornos das políticas sociais diretamente entrelaçados na construção de uma educação inclusiva e suas implicações na Educação Infantil, dada a premência da contextualização da relação cuidar-educar em todas as políticas sociais, na construção de uma educação que valoriza as diferenças.

No artigo "A inclusão na pré-escola obrigatória: uma análise da legislação" Jaqueline Delgado Paschoal discute os efeitos da obrigatoriedade da pré-escola na ação dos 
professores e os desafios para a concretização de um trabalho pedagógico inclusivo de qualidade, em prol do desenvolvimento integral de todos os alunos da Educação Infantil, ao destacar a fragmentação do trabalho pedagógico entre creche e pré-escola, em decorrência da obrigatoriedade de matrícula a partir dos quatro anos de idade, a antecipação da escolarização e alfabetização precoce, bem como a necessidade de superação de práticas escolarizantes de alfabetização, em favor de uma educação que acolhe, humaniza e reconhece a inclusão como direito da criança.

"Normativas oficiais para a Educação Infantil brasileira: desenvolvimento infantil e efetivação da educação inclusiva", de Débora Ribeiro da Silva Campos Folha, Maysa Marinho Antunes Ramos e Patrícia Carla de Souza Della Barba, aborda a concepção de desenvolvimento infantil expressa nas políticas públicas de Educação Infantil e as possíveis reverberações dessa concepção nas práticas inclusivas, bem como a necessidade de intrínseca relação entre Educação Infantil e Educação Inclusiva.

O artigo "Política de inclusão na Educação Infantil: avanços, limites e desafios", de Marilda Moraes Garcia Bruno e Washington Cesar Shoiti Nozu, focaliza a política de inclusão de crianças com deficiência na Educação Infantil, ao apresentar a trajetória legislativa desta etapa de ensino, indicadores de matrículas e resultados de pesquisas sobre a temática. A inclusão na Educação Infantil, no contexto da discussão proposta, é tratada como direito social inalienável, cuja garantia, na perspectiva dos autores, requer práticas colaborativas para a superação da visão instrumental conferida ao Atendimento Educacional Especializado

No artigo "Educação Infantil e Educação Especial: entre as fronteiras do favor e do direito de todos às condições de cidadania" Lázara Cristina da Silva, Vilma Aparecida de Souza e Wender Faleiro, a partir da reflexão sobre as fronteiras existentes entre favor e as conquistas rumo ao direito à educação pública de qualidade referenciada socialmente, desde a promulgação da Política Nacional de Educação Especial na Perspectiva da Educação Inclusiva (PNEEPEI), problematizam a constituição da Educação Especial na perspectiva inclusiva na Educação Infantil, com destaque, entre outros aspectos, à institucionalização das parcerias público-privadas, como uma forma de retorno e manutenção do favor em detrimento do direito à educação de todos às condições de cidadania.

$\mathrm{O}$ artigo "Inclusión en educación: perspectivas que rozan lo político y cincelan lo humano", de Marta Sipes, descreve as inter-relações entre macro e micro políticas educacionais que dão forma e conteúdo à articulação entre escolas de educação especial e 
escolas regulares ou comuns de educação. Abrange um itinerário que analisa as políticas públicas, as teorias implícitas e as ações do cotidiano das salas de aula, permeando como se define nesse jogo dialético uma forma específica do humano: o aluno especial.

No artigo "O lugar das crianças com deficiências na Educação Infantil e políticas de inclusão na educação brasileira", Solange Aparecida de Souza Monteiro e Paulo Rennes Marçal Ribeiro problematizam a invisibilidade conferida às crianças com deficiências de zero a cinco anos de idade, da Educação Infantil, nas ações e políticas promovidas pelo Estado na educação brasileira, frente às suas demandas e ao modo como são compreendidas nos processos educativos.

"Atendimento educacional especializado (AEE) na Educação Infantil: entraves e possibilidades", de Gabriela Machado e Morgana de Fátima Agostini Martins, apresenta os resultados de uma pesquisa que buscou compreender o Atendimento Educacional Especializado na Educação Infantil em Dourados/MS, bem como destaca a necessidade de investimento na infraestrutura para a oferta de AEE na Educação Infantil e na formação do professor especialista, frente às especificidades das crianças nesse contexto educacional.

A temática da acessibilidade é tratada no artigo "Acessibilidade e Educação Infantil: o processo de inclusão do público-alvo da Educação Especial em Manaus/AM", por Maria Almerinda de Souza Matos, Danilo Batista de Souza e Jáima Pinheiro de Oliveira, articulada ao processo de inclusão do público-alvo da Educação Especial na Educação Infantil em Manaus (AM), com ênfase na perspectiva do desenho universal na edificação de espaços escolares que levem em conta suas possibilidades de uso por todos os alunos.

"Um encontro com a diversidade na Educação Infantil por meio do projeto “Simplesmente Diferente" sob a perspectiva do professor, da criança e da família", de autoria de Luciana Aparecida de Araujo, Ana Paula Cordeiro e Claudia Regina Mosca Giroto, tematiza, sob a perspectiva inclusiva, as concepções sobre diversidade junto às crianças de uma classe de Educação Infantil II, seus familiares e professora, a partir do projeto "Simplesmente Diferente", elaborado e desenvolvido colaborativamente por meio de projetos de trabalho, bem como indica possibilidades de trabalho educativo que valorizam a discussão sobre diversidade, nesse contexto educacional, compreendida como constitutiva das relações sociais.

Apresentado por Cláudia Rodrigues de Freitas e Claudio Roberto Baptista, o artigo "Mais rápidas que a escola: crianças referidas como hiperativas no contexto escolar" contempla uma análise cartográfica da atenção, a partir de discursos que identificam, no 
contexto da Educação Infantil, um número expressivo de crianças com hiperatividade e da discussão sobre a construção do conceito de Transtorno de Déficit de Atenção com Hiperatividade (TDAH). Ressalta indícios do discurso médico presente nas escolas e da desvalorização das relações, perspectivados sob uma compreensão biologizante, que evidencia a atenção "[...] em seu movimento circular de invenção, como efeito da/na aprendizagem".

No artigo "Discursivização sobre "doenças do não aprender" no contexto educacional inclusivo: o que dizem os professores de educação infantil?" Claudia Regina Mosca Giroto, Luciana Aparecida de Araújo e Fabiana Cristina Frigieri de Vitta discutem a discursivização, por parte de professores, sobre as "doenças do não aprender" na Educação Infantil, frente ao excessivo aumento de encaminhamentos e diagnósticos, bem como problematizam possíveis implicações na prática docente submetida à lógica medicalizante, nesse contexto.

“Atraso no desenvolvimento e inclusão: a opinião de profissionais do berçário", de Fabiana Cristina Frigieri de Vitta, Mariana Martins Mouro e Ana Júlia Ribeiro Sgavioli, destaca as concepções de profissionais de Educação Infantil sobre o papel do berçário como ambiente favorável para o oferecimento de atividades intencionais que contribuem para a qualidade do desenvolvimento integral do bebê, bem como problematiza a formação docente voltada à valorização das diferenças nesse contexto educacional.

$\mathrm{O}$ artigo "Experiências e apontamentos de professoras de creche sobre inclusão escolar", de autoria de Carla Cilene Baptista da Silva e Andrea Perosa Saigh Jurdi, ao problematizar as experiências em educação inclusiva de professoras que atuam em creches públicas, com crianças de zero a três anos, destaca a necessidade de fomento a práticas intersetoriais nesse contexto.

"A concepção docente em uma experiência de Educação Infantil inclusiva: um estudo de caso" é apresentado por Mariana Picchi Salto e Relma Urel Carbone Carneiro. Nesse artigo as autoras discutem a atuação docente com uma criança com a síndrome $C r i d u$ Chat, a partir da qual apontam a precarização da formação docente para a constituição da Educação Infantil inclusiva.

No artigo "A participação de uma criança com síndrome de down em práticas pedagógicas na Educação Infantil” Jáima Pinheiro de Oliveira e Mariane Andreuzzi Araujo discutem situações de mediação e práticas pedagógicas que interferiram de maneira positiva junto ao acesso curricular e à interação social de uma criança com Síndrome de Down, 
assentadas sob a perspectiva de que a qualidade dessas interações interfere na participação da criança nas atividades realizadas no contexto da Educação Infantil inclusiva.

$\mathrm{O}$ artigo "O envolvimento entre família-escola de pré-escolares com deficiência, dificuldades escolares e desenvolvimento típico", de Danielli Gualda Marins e Fabiana Cia, contempla o envolvimento entre família-escola no processo educacional de crianças com deficiências, dificuldades escolares e desenvolvimento típico, a partir da compreensão de que são necessárias intervenções focadas na família e na escola, com vistas à articulação conjunta de estratégias que fomentem o envolvimento compartilhado de qualidade, em tal processo.

Esses artigos, sob distintos enfoques teórico-metodológicos e a partir de diferentes aspectos que perpassam a articulação entre os princípios da inclusão e da Educação Infantil, suscitam, sem dúvida, o debate acerca da complexidade da constituição de uma perspectiva inclusiva nessa modalidade educacional. Sob a expectativa de que possam contribuir para reflexões e proposições que visem a ressignificação da Educação Infantil como espaço de constituição da heterogeneidade e valorização das diferenças, desejamos a todos uma boa leitura!

Organizadoras

\section{Como citar}

GIROTO, Claudia Regina Mosca.; VITTA, Fabiana Cristina Frigieri de.; ARAUJO, Luciana Aparecida. Dossiê Inclusão e Educação Infantil. Revista Ibero-Americana de Estudos em Educação, Araraquara, v. 14, n. esp. 1, p. 635-640, abr. 2019. E-ISSN: 1982-5587. DOI: 10.21723/riaee.v14iesp.1.12214

Data de Submissão: 10/07/2018

Aprovado em: 10/09/2018 